\title{
Diversidade de Euphorbiaceae em Feira de Santana, Bahia, Brasil
}

\author{
$\underline{\text { Kelle da Silva Cardoso }} \mathbf{1}$ e Daniela Santos Carneiro Torres ${ }^{2}$ \\ 1. Bolsista PROBIC/UEFS, Graduando em Ciências Biológicas, Universidade Estadual de Feira de Santana, e-mail: \\ kellybio@outlook.com \\ 2. Orientadora, Departamento de Ciências Biológicas, Programa de Pós-graduação em Botânica- PPGBot, \\ Universidade Estadual de Feira de Santana, e-mail: dscarneiro@hotmail.com
}

PALAVRAS-CHAVE: Diversidade; euphorbiaceae; taxonomia.

\section{INTRODUÇÃO}

A família Euphorbiaceae passou por profundas modificações com base nos estudos filogenéticos com dados moleculares (Wurdack et al. 2005; APG III 2009), em relação a tradicional classificação proposta por Webster (1994), que dividia a família em cinco subfamílias. As subfamílias que apresentam dois óvulos por lóculo (Phyllanthoideae e Oldifieldioideae), atualmente formam as famílias Phyllanthaceae, Peraceae, Putrangivaceae e Picodendraceae (Wurdack et al. 2005; APG III 2009).

Euphorbiaceae é uma das maiores, mais diversas e complexas família das Angiospermas, são registrados ca. 245 gêneros e aproximadamente 6.300 espécies distribuídas em todo o globo, principalmente nas regiões tropicais (Wurdack et al. 2005). Apresenta uma morfologia bem complexa, sendo caracterizada por diferentes tipos de hábitos, geralmente apresentam látex, vários tipos de tricomas (simples, urticantes, estrelados ou lepidotos) e de inflorescências (panículas, racemos, espigas, tirsos, dicásios, ciátios ou solitárias), presença de flores unissexuadas, ovário súpero, tricarpelar, trilocular com um óvulo por lóculo. O fruto comumente conhecido como tricoca e possui deiscência elástica.

Segundo Cordeiro et al. (2015) o Brasil possui uma alta diversidade de espécies de Euphorbiaceae (ca. 1.000 spp), distribuídas em ca. 63 gêneros. Sua distribuição é ampla, possuindo representantes em todos os diferentes tipos de vegetação do país. No estado da Bahia ocorrem ca. 40 gêneros e 260 espécies (Cordeiro et al. 2015), ocorrendo em cerrado, caatinga, florestas e campo rupestres, evidenciando-se a importância do estudo taxonômico do grupo.

As Euphorbiaceae incluem diversas espécies de interesse econômico. Destaca-se a seringueira (Hevea brasiliensis (Wild. ex A. Juss.) Müll.Arg., a mandioca, aipim ou macaxeira (Manihot esculenta Crantz.), a mamona (Ricinus communis L.), e algumas espécies são utilizadas como ornamentais (Euphorbia L. e Acalypha L.) (Souza \& Lorenzi, 2012). Algumas espécies são marcadoras de ecossistemas como espécies de Croton L., Cnidoscolus Pohl. e Jatropha L. que são características de áreas secas (Caatinga), Alchornea Sw. característica de matas ciliares e campos rupestres e Dalechampia L., Mabea Aubl., Plukenetia L. e Romanoa Trevis., que ocorrem em matas (Heywood et al. 2007; Souza \& Lorenzi, 2012).

Foi realizado o levantamento florístico da família Euphorbiaceae no município de Feira de Santana, contribuindo para a taxonomia da família e conhecimento do grupo para a Flora da Bahia. Incluindo a identificação de gêneros e espécies de Euphorbiaceae, 
caracterização morfológica, elaboração de chaves de identificação para gêneros e espécies nativos de Feira de Santana.

\section{METODOLOGIA}

A área de estudo, o Município de Feira de Santana, está localizada entre as coordenadas $12,25^{\circ} \mathrm{N}$ e $38,96^{\circ} \mathrm{O}$, e inserida no Bioma Caatinga, incluindo oito distritos sendo eles: Bonfim de Feira, Jaguará, Governador João Durval Carneiro, Humildes, Jaíba, Maria Quitéria, Matinha e Tiquaruçu.

Foi realizado o levantamento bibliográfico sobre a família Euphorbiaceae, consultando monografias, artigos e floras.

Coletas foram realizadas em Feira de Santana, para obtenção de amostras e observação das espécies em campo. As descrições foram feitas a partir dos materiais de Feira de Santana depositados no (HUEFS), para os dados de morfologia foi utilizado Radford et al. (1974), Vidal \& Vidal (2003) e o Gonçalves \& Lorenzi (2007). Foram elaborados comentários, chaves de identificação para gêneros e espécies de Euphorbiaceae.

Foram analisadas 230 exsicatas, sendo que destas 14 tiveram as suas identificações atualizadas.

\section{RESULTADOS E/OU DISCUSSÃO}

Em Feira de Santana foram encontrados 19 gêneros e 58 espécies sendo: Acalypha (A.amblyodonta Mull.Arg., A. brasiliensis Mull.Arg., A. communis Mull.Arg. e A. weddeliana Baill.); Adelia (A. membranifolia (Mull.Arg.) Chodat \& Hassl.), Actinostemon (A. appendiculatus Jabl., A. concolor (Spreng) Mull.Arg. e A. verticillatus (Klotzsch) Baill.) Bernardia (B. tamanduana (Baill.) Mull.Arg.); Bia (B.lessertiana Baill.); Cnidoscolus (C. loefgrenii (Pax \& K.Hoffm.) Pax \& K.Hoffm., C. marcgravii Pohl. e C. urens (L.) Arthur.); Croton (C. adamantinus Mull.Arg., C. argyrophyllus Kunth., C. glandulosos L., C. grewioides Baill., C. heliotropiifolius Kunth., C. hirtus L'Her., C. pedicellatus Kunth., C. pulegiodorus Baill., C. sonderianus Mull.Arg., C. tetradenius Baill., C. triqueter Lam e C. urticifolius Lam); Dalechampia (D. brasiliensis Lam.,D. peckoltiana Mull.Arg. e D. schenckiana Pax \& K.Hoffm.); Ditaxis (D. desertorum (Mull.Arg.) Pax \& K.Hoffm.); Euphorbia (E. adenoptera Bertol., E. comosa Vell., E. heterophylla L., E. hirta L., E. hyssopifolia L., E. insulana Mull.Arg. e E. prostrata Aiton.); Gymnanthes (G. boticário Esser. e G. klotzsckiana Mull.Arg.); Jatropha (J. curcas L., J. gossypiifolia L. e J. mollissima (Pohl) Baill.); Maprounea (M. guianensis Aubl.); Microstachys (M. corniculata (Vahl) A. Juss. ex Griseb.); Manihot (M. anomala Pohl., M. carthagenensis (Jacq.) Mull.Arg. e M. epruinosa Pax \& K.Hoffm.); Philyra (P. brasiliensis Klotzsch.); Ricinus (R. communis L.); Sapium (S. glandulosus (L.) Morong.); Sebastiania (S. brasiliensis Spreng., S. jacobinensis (Mull.Arg.) Mull.Arg. e S. riparia Schrad.) e Tragia (T. volubilis L.).

Os gêneros que apresentaram maior diversidade de espécies foram Croton e Euphorbia com 12 e sete espécies (Figura 1), respectivamente. Isso pode estar relacionado a localização de Feira de Santana, inserida na região semiárida, onde essas espécies são mais diversas ou por se tratar dos maiores gêneros da família. O gênero Croton é 
caracterizado por apresentar tricomas variando do estrelado ao lepidoto nos ramos, inflorescências racemosas geralmente com flores estaminadas diclamídeas e dispostas no ápice da raque e as flores pistiladas monoclamídeas dispostas na base, enquanto que o gênero Euphorbia é identificado por apresentar inflorescência pseudantial do tipo ciátio, geralmente com diferentes tipos de nectários e apêndices, e com flores estaminadas reduzidas a um único estame e a flor pistilada localizada no centro do ciátio, ambas aclamídeas.

Para Acalypha, foram registradas quatro espécies (Figura 1), enquanto que Actinostemon Klotzsch., Cnidoscolus, Dalechampia, Jatropha, Manihot Miller. e Sebastiana apresentaram três espécies cada. Apesar destes gêneros serem bem amostrados em áreas de caatinga são menos diversos que Croton e Euphorbia.

Os demais gêneros (Adélia L., Bernardia Miller., Bia Klotzsch., Ditaxis Vahl ex Juss., Maprounea Aubl., Microstachys A. Juss., Philyra Klotzsch., Ricinus, Sapium Jacq. e Tragia L.) foram pouco representativos com uma espécie cada (Figura 1). O gênero Adelia é representado na Bahia apenas pela espécie A. membranifolia (Mull.Arg.) Chodat \& Hassl., sendo encontrada também na região de Feira de Santana. Esse gênero é caracterizado principalmente por apresentar plantas dióicas com longos espinhos nos ramos, inflorescências solitárias ou geminadas, e as flores estaminadas são diclamídeas e as pistiladas monoclamídeas.

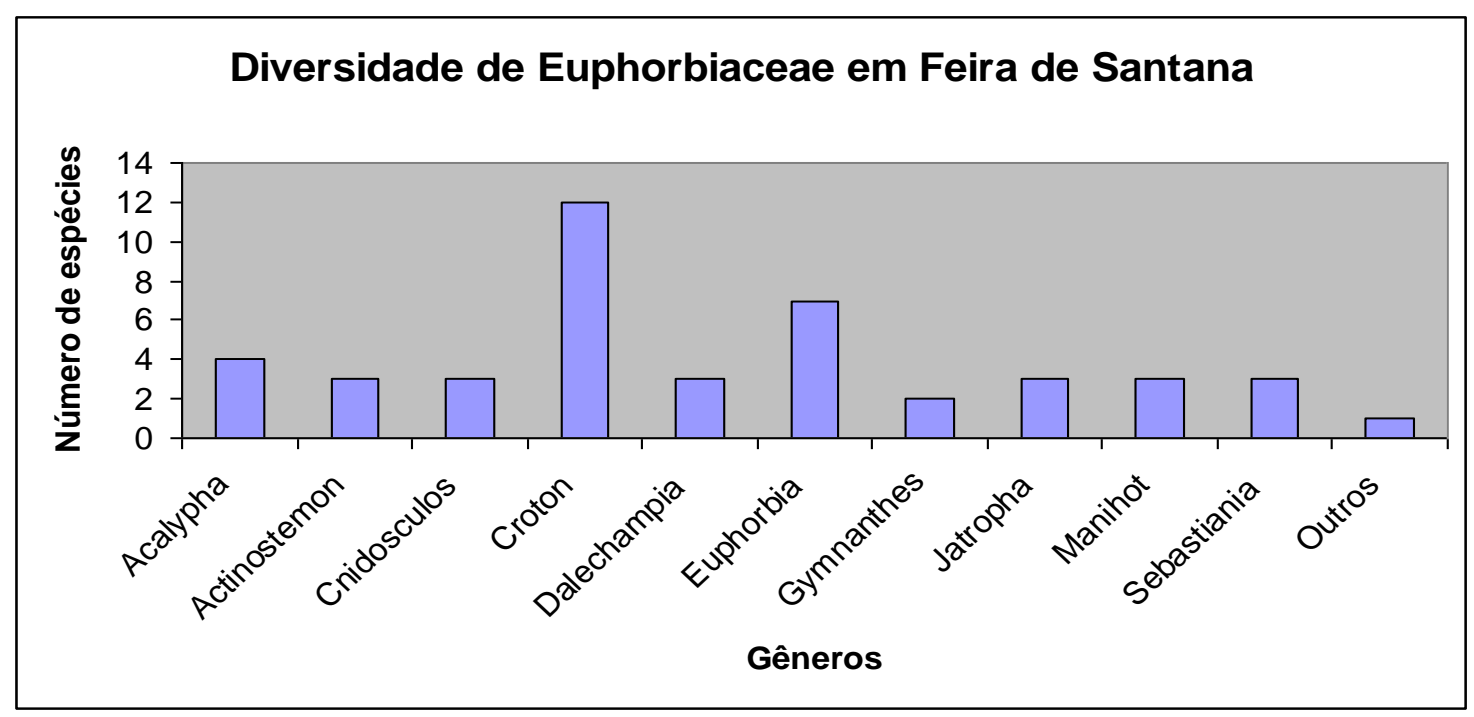

Figura 1. Diversidade de Euphorbiaceae em Feira de Santana.

\section{CONSIDERAÇÕES FINAIS}

Em Feira de Santana foram registradas 58 espécies da família Euphorbiaceae distribuídas em 19 gêneros, sendo que os gêneros Croton e Euphorbia são os que possuem mais representantes, estes são gêneros típicos de regiões semi-áridas. A família possui uma grande diversidade em todos os tipos vegetacionais, por isso é de fundamental importância trabalhos de levantamento florístico para auxiliar no conhecimento da família e na formação de taxonomistas. 


\section{REFERÊNCIAS}

APG III. 2009. An update of the Angiosperm Phylogeny Group classification for the orders and families of flowering plants: APG III. Bot. Journ. Linnean Society 161:105121.

CORDEIRO, I et al. 2015. Lista de Espécies da Flora do Brasil. Rio de Janeiro: Jardim Botânico do Rio de Janeiro. (http://floradobrasil.jbrj.gov.br/2012/FB000113).

GONÇALVES, E.G \& LORENZI, H. 2007. Morfologia Vegetal. Instituto Plantarum de Estudos da Flora LTDA. 416p.

HEYWOOD, V.M et al. 2007. Flowering Plant Families of the World. Firefly Books, $424 p$.

RADFORD A.E et al. 1974. Vascular plant systematics. New York: Harper \& Row. 891pp.

SOUZA, C. V. \& LORENZI, H. 2012. Botânica Sistemática: guia ilustrativo para identificação das famílias de Angiospermas da Flora Brasileira, baseado em APG II. Nova Odessa, SP: Instituto Plantarum.

VIDAL, W.N \& VIDAL, M.R. 2003. Botânica Organografia: quadros sinóticos ilustrados de fanerógamos. Viçosa: UFV. 124p.

WEBSTER, G.L. 1994. Synopsis of the genera and suprageneric taxa of Euphorbiaceae. Annals Missouri Bot. Gard. 81: 33-144.

WURDACK, K. J.; HOFFMANN, P.; CHASE, M. W. 2005. Molecular phylogenetic analysis of uniovulate Euphorbiaceae (Euphorbiaceae sensu stricto) using plastid RBCL and TRNL-F DNA sequences. Amer. Journ. Bot., v. 92, n. 8, p.1397-1420. 